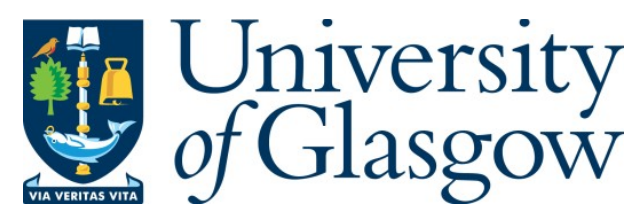

McDonnell, L., Scott, S., and Dawson, M. (2016) A multi dimensional view?

Evaluating the different and combined contributions of diaries and interviews in an exploration of asexual identities and intimacies. Qualitative Research, (doi:

10.1177/1468794116676516).

There may be differences between this version and the published version. You are advised to consult the publisher's version if you wish to cite from it.

http://eprints.gla.ac.uk/129818/

Deposited on: 10 October 2016

Enlighten - Research publications by members of the University of Glasgow http://eprints.gla.ac.uk 


\title{
A multi dimensional view? Evaluating the different and combined contributions of diaries and interviews in an exploration of asexual identities and intimacies.
}

\author{
Liz McDonnell, Susie Scott and Matt Dawson
}

Universities of Sussex and Glasgow

\begin{abstract}
This paper evaluates the combined and differential contributions of diaries and interviews in qualitative research concerning asexual identities and intimacies. These methods each had the potential to provide a different focal point for our participants (we use the metaphors of wide-angle and telephoto lenses) thus generating a multi dimensional view of our topic. Using five cases in which data from both interviews and diaries were collected, this paper explores how the intermeshed issues of identity and intimacy were constructed in each method, as well as reflecting on what was gained by their combination. Our analysis leads us to conclude that multiple methods do not always produce a fuller or a more rounded picture of individual participants' lives. Nor do they necessarily produce different types of data. Nevertheless, the decision to collect data using different strategies did increase our chances of finding a method that suited individual participants, whether in style or focus.
\end{abstract}

\section{Multiple methods}

Using more than one method of data collection and/or analysis in research is a well established tradition in the social sciences (Alexander et al, 2008). The particular mixing of qualitative and quantitative methods, often called mixed-methods research, has received the greatest attention in recent years, and more recently has come to be seen as having intrinsic value (Mason, 2006). Some might argue that mixed-methods have become a third way in social research (Bryman, 2006) in addition to the traditional (and much critiqued dichotomy) between qualitative and quantitative paradigms (Oakley, 1999; Mason, 2006). Researchers have also chosen to mix more than one quantitative method e.g. Fielding et al (2007) and to mix different qualitative methods e.g. Bagnoli (2004).

Whatever combination of methods a researcher chooses to use, two key concerns emerge: rationale for their use and, how the different sets of data will be integrated 
(Moran-Ellis et al, 2006). Rationales tend to focus on validation of data or analysis and/or gaining a fuller picture of the subject under investigation (Mason, 2006). In its classical form, the validation rationale rests on the assumption that mixing methods allows researchers to avoid the biases and blindspots inherent in each method (Monrad, 2013). Also, if each method produces similar results, then the phenomenon has been accurately measured (Moran-Ellis, et al, 2006). More modest triangulation claims are encapsulated in Greene et al's (1999) notion of complementarity where multiple methods can be seen to capture the complexity or different aspects of a phenomenon. Mason (2006) adds that mixed methods allow us to explore complex social experiences and lived realities along various dimensions - so multi-dimensional realities can be captured.

The second question of how different types of data are integrated has been usefully explored by Moran-Ellis et al (2006). They argue that integration involves the retention of each method's distinct paradigm but at the same time finding ways to intermesh the mixed data, so that more is known about the research topic. Intermeshing becomes possible through the generation of a tangible relationship among different types of data, methods or perspectives. Moran- Ellis et al use an approach called 'following a thread' where after each dataset has been analysed inductively, analytic questions or themes emergent in one dataset are followed up in others.

\section{Integrating multiple qualitative methods}

The usefulness of multiple method approaches in the study of intimate relationships has been recognised (Gabb, 2009; Jamieson, 2011). In our project about asexual identities and intimacies, we used methods that asked participants to approach the research topics from more than one angle. Researcher-led diaries and biographical narrative interviews differ in their reflective time-frame (the day just had/lifetime), context (alone/with researcher) and mode (written/verbal). Given these differences, we wanted to explore the ways in which each method produced different types of data, as well as the extent to which the data produced could be interweaved. Consistent with an interpretivist approach (Blaikie, 1993), we were not pursuing a definitive truth about our participants' experiences; rather, we recognised that multiple methods facilitated different understandings of how people comprehend and narrate their lives. In more practical terms, we expected that our use of multiple methods would increase the chances of getting at least one method that was appropriate for individual participants (Harris et al, 2014).

Our first method was an adapted version (for practical reasons) of the biographical narrative interview method. Biographical narrative interviews focus on storytelling and are concerned with the many and different, past and present, dominant and less 
important, perspectives people have on their life experiences (Wengraf, 2001). Stories are elicited through questions that ask participants to give detailed accounts of particular incidents in their lives. In our study, the main body of interview data was collected as a result of the question - "What have been the key incidents and experiences around asexuality in your life?" Interviews of this sort are cross-sectional, collecting a snapshot of a life at one point in time. They encourage reflection across a lifetime, focusing on distant as well as recent events. We imagined that the reflective element would require the participants to take a wide angle lens to their lives, allowing more biographical information to be covered and to magnify the distance between different elements of the stories told. Additionally, interviews involve 'live' social interaction between participants and researchers, whereby the active processes of probing, questioning and non-verbal communication inevitably shape the narrative accounts of knowledge that are co-produced (Holstein and Gubrium, 1995); Briggs, 1986; Solberg, 2014). It is not possible in this paper to evaluate and account for the myriad ways in which the 'interactional effect' shaped the interview data. Four out of five of the interviews used in this paper were conducted by the main interviewer for the study who brought with her many years of interviewing experience, as well as positionalities relating to her class (middle class), race (white), gender (female) and someone who experienced sexual attraction (i.e. non-asexual).

The second method we used was the researcher-driven diary, which aims to collect information about a particular issue over time (Elliott, 1997). This can be more or less structured (Harvey, 2011), and has been used in qualitative research to explore emotions and interactions within family life (Gabb, 2009), sexual acts and their context (Coxon, 1988), condom use in heterosexual relationships (Harvey, 2011) and the emotions of snowboarding mothers (Spowart and Nairn, 2014) among other issues. The advantages of researcher-diaries include increased agency of participants in determining how and when they disclose information (Markham and Couldry 2007), capacity to log everyday routines (Gabb, 2009) and processes and reduced recall and memory errors (Verbrugge, 1980). Alaszewski (2006) argues that diaries allow variation, creativity and flexibility in the stories and events produced. Diaries can also provide access to private spheres which may be difficult to observe or record (Coxon, 1996), sometimes because of their sensitive nature (Kenten, 2010). Conversely a two week diary is potentially demanding and onerous in terms of participants' time. Ethical issues also arise in terms of mental intrusion e.g. bringing attention so regularly to a potentially sensitive issue within participants' sense of self or relational life. Accordingly, this intrusion might increase the chances of non-responses.

Diaries collect longitudinal data (in our study this was over a two week period) and evoke short-term reflections on the day that has just been. We asked three daily questions in the diary that related to everyday experiences and interactions around: 
being aware of asexuality; feelings of closeness to people or things; and difficulties linked to asexuality in close relationships. More broadly we conceptualised the diary as providing a telephoto lens, magnifying the subject more, with a narrow field of view. In all but one case, diaries followed interviews, with this one divergent case being due to practicalities for the participant. We also asked for feedback on the diary-writing process, and include some comments on this in our analysis.

The questions we asked in the diaries and interviews were intermeshed, focusing on our dual research interests of asexual identities and intimacies, although in different ways and with different emphases. For example, one of the three diary questions related to identity and two to intimacy. Within the interview schedule we expected issues around both identity and intimacy to arise in significant asexuality-related events as well as asking specific questions about identity.

In theoretical terms, too, our topics of identity and intimacy were interrelated. Our starting point was the idea that personal social life is grounded in 'relationality', a concept that assumes that people live within intentional, thoughtful networks of others which they can maintain, actively sustain or allow to atrophy (Smart, 2007). Connected to this is the idea that identity or sense of self is relational and is mediated through interactions with others as well as private sense-making (Williams, 2000). Consequently, intimacy shares an interdependent and mutually constitutive relationship with identity; the sense of self we get or do not get in close relationships matters to how we see ourselves (see Sanger 2010).

\section{Positioning asexuality}

Since the turn of the $21^{\text {st }}$ century asexuality has been the subject of increasing attention from researchers, emerging for the most part from psychology (Bogaert, 2006; Prause and Graham 2007), psychiatry (Brotto et al. 2010) and demography (Bogaert, 2010). Running parallel to recent research activity around asexuality has been an emergent asexual movement, with a strong online presence and a political agenda of establishing asexuality as a legitimate sexual identity (Milks \& Cerankowski 2014). The Asexuality Visibility and Education Network (AVEN) has spearheaded attempts to normalise asexuality and provides multiple fora for education and discussion. AVEN defines asexual people as 'those who do not experience sexual attraction' (AVEN, 2015), however as Carrigan (2011) notes, this straightforward definition masks a diverse body of individuals with ranging attitudes and behaviours in relation to sex and romantic attraction (Van Houdenhove et al, 2014). This implies complex, ever evolving terminologies as well as identities. 
In the social sciences, there has been a welcome move away from the classification and categorisation of asexual 'types' to a focus on asexual identity (Scherrer, 2008; Carrigan, 2011; Chasin, 2011). For example, within cultural and gender studies, research and theorising has considered how asexuality problematises the dominance of 'Sexusociety' (Pryzbolo, 2011). However, the research project we discuss here shifted the focus away from asexuality in terms of what it does, and the individualised ways in which it is acquired as an identity, to a consideration of how plural asexual identities develop through social interaction. Over the life course, these career trajectories (Glaser and Strauss, 1971) involve an ongoing process of 'becoming' (or indeed 'nonbecoming' ([Author B et al, 2016]) rather than purely 'being' (Becker, 1963). In our research, we sought to explore the ways in which asexual lifestyles are the outcomes of meaningful social action constructed over the life course, and how these aspects are expressed via everyday practices which are negotiated in social interaction. Following on from these relational aspects of asexual identity, the research also sought to understand how intimacy was constructed and maintained in relationships where one, or both, people identified as asexual (Author $\mathrm{C}$ et al, in press). Asexuality therefore complimented our above theoretical and practical concern with the interconnection of identity and intimacy.

\section{The study}

Our sampling process involved advertising for participants through online communities such as AVEN, local LGBTQ groups in two UK cities, an article written for Huffington Post and adverts in local libraries and community organisations. We were keen to minimise the effects of sampling from organisations such as AVEN, which in other studies had produced samples skewed towards younger women, with higher levels of education, who were middle class, white and American (e.g. Scherrer, 2008). Therefore, once we discovered we had over 100 volunteers from these various fora we first contacted those who were male and over the age of $30 \mathrm{yrs}$. The rest of the sample was decided by a random number generator applied to the remaining group of participants.

In terms of information given in our pre-interview, short demographic information form, the majority of participants normally resided in the US (24) or the UK (14) and most were women (30). Most of the participants were aged under 29 (38), relatively well educated (25 participants had a university/college degree), described themselves as single (36) and ethnically identified as white (37). We conducted 50 biographical narrative interviews by Skype and face to face; 27 people also completed diaries. For the purposes of this paper we will focus on 5 cases of people who completed both the diaries and interviews. Each of these cases represent one of five analytical categories (Non-engaging, Troubling, Seeking romance, Negotiating and Pioneering) that we developed to characterise the stories told, according to (1) the way people positioned 
themselves in relation to romantic attraction and/or sexual/sensual desires, and (2) their strategies for managing these positions in different social relationships (Author A and B, 2015).

Using case studies, the aim of this paper is to explore in more detail how the diaries and interviews provided different perspectives on our research topics and taught us different things about multiple methods research. By comparing the accounts given in each person's diary and interview, we assess whether and to what extent our use of multiple methods really created a fuller multidimensional view of our research concerns.

\section{Case Studies:}

\section{Horses for courses: methodological self-sufficiency and superfluousness}

Freya (Pioneering Group, 24-29 yrs. old, self-identified 'asexual heteromantic' and single)

Freya's interview was long and detailed, giving a very full picture of her life experiences that related to both identity and intimacy. The interview provided a space in which she was able to articulate a wide angle perspective on her experiences as well as a telephoto focality as she also provided detailed excerpts from her life. Consistent with many of our interviews, Freya's story started with finding out about asexuality online and how that provided security and comfort in terms of her self-perception. She had identified variously as queer, bisexual and 'not heterosexual' for many years before finding out about asexuality when she was twenty-five years old. Despite claiming this label privately, Freya had not told anyone she was asexual although she recognised there had been opportunities to do this. She expressed concern that people would not understand, and ambivalence about the need to come out as asexual (because people already knew her as queer). Nevertheless, she wanted to share her new identity, suggesting an awareness of the positive cultural norms around public accounts of authentic selves (Plummer, 2003).

\section{I: Have you come out to anyone?}

P: No... I think everyone knows that I'm queer in some way, so I don't feel the need to give them another label that most of them probably won't understand... But at the same time, I want to share this, because now it's right.

In terms of intimate experiences with others, Freya had had what she called a semi-poly relationship (her only relationship to date) with a couple throughout two years at university and although she did not live with them, she was often with them. Being a 
third party to a married couple or 'second choice' to one of them was her ideal relationship.

\section{I: So have you had any experience of relationships or any kind of....?}

P: ... After school I went there instead of home to my place... and we lived and we cooked and we did laundry together and all those things. And then he went to bed, and then me and the girl/wife/woman stayed up and did all those stupid things that you do when you're a teenager and your parents had gone to bed. We ate cookie dough and we watched movies until late at night.

Freya demonstrated a remarkably agentic approach to finding different kinds of relationships in which she could feel special and loved, and so appeared pioneering in her approach. She also had two other significant women in her life: a 'girlfriend' who accompanied her to college, and on various day activities and a 'mistress', described as a 'best friend', with whom she travelled. Freya made the point that these significant others were all heterosexual women and that she needed them not to be sexually interested in her, to give her freedom to be intimate with them.

In contrast to the interview where Freya was able to talk at length and in detail about both her asexual identity and experiences of intimacy, her diary contained lots of empty spaces (particularly around the identity question) and she did not report any everyday experiences in which asexuality had created difficulties in her relationships, perhaps due to the pioneering approach discovered in her interview. She noted the discomfort she felt having to focus on her asexuality so much in the diary:

The main way I became aware - or was aware - about my asexuality today was that I thought about this project. I was all of a sudden painfully aware that I needed to pick up on/remember things that I perhaps usually would brush aside and forget about.

Freya was not alone in reporting feelings that the diary sometimes triggered a different kind of self-awareness, and this was not always welcomed. This may be particularly true when the identity category is poorly understood and/or hidden. Participants who were not especially engaged with their asexuality as a positive or important identity (Author B et al 2016) and/or did not want to ruminate further on it, were particularly likely to express such discomfort. This also highlights the potentially burdensome nature of the diary method: perhaps that the subject of identity - when not at the forefront of someone's mind in an everyday sense - is best explored by the interview 
method, where there is space for the wide-angle lens and without daily reminders of the identity category.

Nevertheless, and consistent with the interview, Freya's everyday life as reported in the diary, contained reports of interactions and experiences that connected her to meaningful and loving relationships with friends and family. In this case study, although the diary provided some useful examples of moments of intimacy, it did not add significantly to our understanding of asexual identity and intimacy in Freya's life. The diary data were almost superfluous in comparison to the rich data provided by the interview. Within one research method alone (the interview), Freya was able to bring both a telephoto and wideangle focus to her life, and so did not need the second method. This highlights the ways in which participants make use of the methods offered and that some methods are better suited to some participants than to others. In feedback on the diary process, she added that she sometimes felt she was 'letting us down' by not having enough information to talk about and conversely wanting to summarise the 'rambly bits' so that we did not have to wade through too much information she had already given. The conjunctive use of two methods also raises questions of participant self-censorship to avoid repetition. Additionally, it is possible that Freya was more comfortable narrating her life through the spoken interview than in writing.

\section{Agentic revelations: participants' interpretations and use of methodological tools}

\section{Liam (Troubling Group, 18-23 yrs. old, self-identified aromantic asexual and single)}

In contrast to Freya, Liam's diary provided a richness of data that was absent in his interview. He was the only participant to complete his diary before doing an interview, which may have meant his diary contained more contextualising information, with the first episode of data collection being an opportunity for scene-setting. Liam wrote his diary entries while working at a summer camp, and he mentioned that the diary-writing had been 'soothing' and made him 'more confident in being asexual'. He chose to write the diary during summer camp as he anticipated having 'a lot of stuff to talk about'. Liam took his participation in the research as an opportunity to perform reflective biographical sense-making (Holstein and Gubrium, 2000) or 'identity work' (Snow and Anderson, 1987) by working through emotional issues in reflective writing as if thinking aloud. It is also important to note that Liam did not use the diary format we gave, choosing instead to create his own unstructured entries, although all of his entries did refer back to the themes in the questions we asked. This agentic approach to 
research participation may also have allowed a greater flow of personal material to emerge and fitted his preferred (written) mode of conversation.

Two major and interwoven themes emerged in Liam's diary: feeling different from others (and bad about himself) and his struggle to get the physical and emotional intimacy he desired. Feeling different emerged in his observations of others (both generalised/unknown as well as personally known). This highlights the pervasiveness of sexual and romantic cultural narratives at the micro-level. Our sense of self arises out of observations and imaginings about others, as suggested by Cooley's (1902) concept of the 'looking glass self'.

I have the frequent problem of feeling bad when I'm with some of my friends constantly talking about their interests in girls throughout the day. Honestly, this camp is one giant hook-up session; they even made a chart to track all of the "camp incest" going on with people hooking up. I find it disgusting.

Liam's diary expressed very complex feelings of rejection, confusion, hurt, and desire for closeness. It showed clearly the dramatic and negative ways in which his thwarted desires for asexual intimacy affected his sense of self. His detailed reporting of multiple interactional scenarios allows us to evaluate both the sequencing of key interactions as well as their personal consequences, as Liam made sense of what happened.

Liam faced difficult negotiations around getting the emotional and physical intimacy he desired. He desperately wanted to be in close physical contact with certain men - to have arms around shoulders, legs touching, to massage and be massaged, and to be cuddled, which, significantly for him, released endorphins. In a previous camp he had received a lot of physical affection from male friends but felt that things had changed when he had come out as asexual. His friends had withdrawn their affection, one saying that he thought Liam was being 'turned on asexually' - that sensual contact was arousing Liam in an 'asexual way' - giving a new unsettling meaning to the exchange of physical contact between them.

Bill told me today that he treats me differently than straight guys and that's why he's not as touchy with me anymore. He doesn't want to cuddle because I'm asexual. Honestly, this killed me and makes me hate being asexual more than anything. I can't focus. I'm just too angry. I hate people.

In contrast, Liam's interview shows that the very act of asking about key events and experiences can lead the interviewee to compartmentalise key aspects of their lives, rather than to simply describe the spontaneously unfolding concerns of the day. Thus in 
his interview Liam talked about finding out about asexuality, coming out experiences, and engaging with the asexual community online, echoing familiar themes embedded in many of our participants' stories and common to standard asexual life story narratives (Carrigan 2011). Liam started his story with an account of teenage confusion and sexual experimentation. He had had a male friend with whom he enjoyed cuddling, and a relationship with a young woman that was both sexual and romantic. He found out about asexuality from a friend at the start of college having experienced some years of uncertainty around his identity.

Echoing the themes in his diary, albeit in a more reserved way, were Liam's 'coming out experiences', which were both positive and negative. He described not being able 'to hold it in anymore' in relation to his college fraternity and that women were generally easier to tell, as long as he trusted their political beliefs. The importance of others' responses to asexuality and the social nature of identity formation were also highlighted in Liam's interview.

The diary format in this case study allowed us to see the relative (and large) emphasis Liam gave to his concerns about intimacy and the consequences for his sense of self as an asexual man. The emotional poignancy and plot detail of interactions was acutely present in the diaries - whereas in the interviews, the wide angle lens made things more distant and circumscribed. The interview also superimposed narrative order onto Liam's story. The diary facilitated our understanding of Liam's daily preoccupations and concerns, how important they were to him and the precise detail of meaningful interactions and encounters. Had we relied only on the interview, we would not have understood the level of conflict and emotional turmoil in Liam's life, nor how experiences around intimacy shaped his self-identity.

\section{Capturing change: sequential ordering and shifting perspectives}

\section{Bea (Seeking Romance Group, 24-29 yrs. old, self-identified heteromantic asexual and single)}

The interview and diary in this case were quite different in tone and focus. This serves to illustrate the point that all research is temporally located; people's lives have the potential to change rapidly and in different directions from one week to the next, and our use of multiple methods allowed us to capture this.

In her interview, Bea presented a calm, processing self who carefully managed her faceto-face dating as well as expressing ambivalence to physical touch and sexual feelings. 
She described asexuality as a relatively private matter, which had never particularly concerned or troubled her.

Bea's first significant event around asexuality was finding out about it on Tumblr; she recalled the subsequent process of researching asexuality online and a gradual claiming of that identity. This had happened at university, and she had not been particularly concerned by her lack of interest in relationships and sex before this point. Coming out experiences and reactions were also significant to her, but these were recalled as positive and unchallenging. Bea was now dating but avoided physical contact and discussing her asexuality with the men involved. It therefore remained a dormant, unproblematised issue:

I: So does a date not get to a stage where it gets...? And who's managing that ...?

P: When I go out on physical dates, it's maybe a kiss on the cheek. Generally, I don't know what they're thinking... they're maybe thinking I'm a little oldfashioned or something, but I've never really progressed far enough that it would get to a point where, in my mind it would be sort of that sex would be the next step...

However, Bea's diary sits in stark contrast to her interview. The diary had a dynamic and excitable feel and included much fast-paced action. Bea described developing an intimate online relationship with a man that she framed as fetish-based, though she linked this to masturbatory pleasure, rather than sexual attraction. Bea positioned sex as an unnecessary but potential element of an intimate scenario in which she achieved orgasmic satisfaction as well as the mental pleasure of her kink.

In the chronology of this new online existence, new ideas emerged, which we would not have understood if we had relied solely on the interview. Bea's very first diary entry was about her experiences of Fetlife - an online site for fetishes - where she indicated an interest in self-bondage. Her second entry was about Victorian erotic photographs and discussions with her flatmate about fetishes they would like to try out. In subsequent entries, she reported that she was talking and 'sexting' with a man on Fetlife, feeling relieved that he was not able to function sexually as this enabled her both to be more open and to avoid being put off by the thought of actual bodily sex. Interestingly, Bea's roommate asked her whether eventually meeting with her friend online might change her 'asexuality thing' and she explained how it might work with him: 
I told her how I don't want to have sex with him. If anything it's assisted masturbation. I feel like using a dildo with him is not having sex with a person, but with an object. I'm all for masturbation and think it's a wonderful thing. I have a strong libido and use masturbation to deal with it.

Bea's diary entries ended with reflections on her developing 'Daddy/babygirl' relationship with Uri, and she wondered what would happen if they met.

The sequential use of mixed methods in this case, showed Bea at more than one point of her life. It captured change, new potentials, and aspects of character that she may not have felt comfortable expressing, or deemed relevant to mention, in the interview. It also showed the shift in her thinking about the link between asexual identity and possible practices of intimacy. Multiple methods therefore produced additional and vital insights into a self capable of change and perhaps a self differently expressed in the diary.

\section{Narrative launching pads: illustration, elaboration and contextual detail}

\section{Idra (Negotiating Group, 18-23 yrs. old, self-identified asexual and in relationship)}

This case study is marked by continuity between the diary and the interview, with two major plot lines (difficulties of coming out and a new relationship), being key foci in both. One can imagine 'narrative launching pads': ideas being flagged in the interview as significant, and then being taken up in the diary with poignancy and depth. This continuity of themes unfolded in a smooth and fluid way, rather than being disjointed. In her interview, Idra recalled feeling different at high school around attractions to boys, and a period of 'trying out sex' with five boys to see if she could feel comfortable and or interested in it. Consequently, she remembered feeling that sex was 'not for me', joining her school's 'Queers and Allies' group, and finding out about asexuality. After researching further, she concluded that she was asexual, and chose to tell her mother and sister. Their reactions were negative and lacking compassion:

After negative responses from friends too, Idra became reluctant to discuss her asexuality with anyone else. This became increasingly relevant as she had started a new relationship; her internalisation of the idea of asexuality being 'weird' and unacceptable, had foreclosed her opportunities to be honest with her partner:

I: So how are you handling that side of things? 
P: So now I'm real nervous to, like, bring that up especially as it's the first time I'm in a relationship again... So... we can, like, make out for a half hour... you can enjoy it ... I'll just sit here and participate....' So I'm just very passive about it... 'Cause I realize there's something that's weird about me...

Idra's diary entries continued with a focus on her relationship with Broc and her everyday negotiations and experiences with him around sexual and other kinds of intimacies. The interview material thus launched plot lines which were more fully explored and developed in the diary. She did mention occasional moments of closeness with her family or friends but said that her asexuality was only relevant in relation to Broc, i.e. regarding sex and intimacy. This shows how asexuality can be a relatively dormant issue in someone's life (as in Freya's case) until issues around intimacy reignite its significance.

Throughout the diary-writing period, Idra did not speak to Broc about her asexuality. This had also been anticipated by the interview, where Idra expressed fears about coming out to anyone else after her experiences with her family. She was therefore left to deal privately with this issue and how it shaped her attitude to sex. Her diary entries made it clear that there were aspects of physical closeness to Broc with which she felt comfortable, such as kissing and cuddling, and she described other pleasurable experiences of intimacy, such as waltzing with him and talking about relationships and family. However, many more of Idra's diary entries revolved around situations arising (if they could not be strategically avoided) that involved unwanted sexual intimacy.

Idra wanted to avoid feeling 'weird' or rejecting Broc, so she described 'go(ing) with the flow' of 'normal couples' in an attempt to maintain a 'normal relationship'. She highlights below how she sex equated sex with normality, but also how she did not have the words to communicate her asexuality:

Having sex is something that we do because I succumb to peer pressure and want to be normal so I go ahead with it. I just wish that I knew how to approach the subject with him and then even know what to say if I did.

By the end of the diary-writing period Idra acknowledged that if the relationship continued, she would have to find a way of broaching the subject of her asexuality. It is possible that writing the diary may have caused her to reflect more deeply on the uncomfortable patterns she was involved in, which raises an ethical concern. Idra hinted at this in her diary-writing feedback, reporting that she had learnt that she was a 'people pleaser', and that she hoped she would find it easier to be open with her boyfriend in the future. 
Idra's diary entries show how this method provided a different kind of space in which to illustrate, elaborate on and substantiate issues that may have only been briefly mentioned in the interview. The details (and their regularity) provided in the diary both in the micro contexts described and in the language used - allowed us, and Idra, to gain greater insights into the dilemmas lightly posed in the interview. The emotional and psychological effort of privately managing conflicts around a desire for a close relationship and lack of interest in sex (a seeming requirement of the relationship), are so clearly stated through the diary medium.

\section{Making sense of empty space}

Lisa (Non-engaging Group, 36-41 yrs. old, self-identified aromantic asexual and single)

In this final case, we explore the use of multiple methods when one produces no additional data. Lisa's interview was very emotional and she articulated profoundly difficult feelings, perhaps for the first time. She presented herself as a person with few social relationships, who was very work-focused, but also struggling with a part of herself that she both accepted and did not accept, simultaneously. In this respect, Lisa gave a full and deeply moving interview but by striking contrast, her diary was completely empty of daily responses. However, unlike in Freya's case (Case 1) when the diary was seemingly superfluous because of the richness of the interview data, the emptiness of Lisa's diary reflected her feeling she had no responses to give in relation to any of the questions asked.

In common with many of the interviewees, Lisa recalled feeling different from others in her teenage years, particularly when people started 'fancying' others. By the time she got to university, a pattern of 'keeping myself to myself' was becoming established and she was unsure how much this feeling of difference from others (concerning sexual attraction), caused her to withdraw socially or whether she just had an 'asocial' (introverted) personality. A privately processed and internally negotiated duality emerged in Lisa's interview around the intersection between asexuality and 'asociality', as she questioned which had emerged first and how they were inter-related:

I: What had life been life before that point-you said you felt different - that you didn't know how to understand that - you didn't have a term or a rationale for that?

P: ... Whether or not that is something completely independent (I'm just not that social) or it's to do with that feeling of there was just something so different about me that I couldn't admit it and maybe at some level I just didn't want to 
get close to anybody that at some point they'd realise that there was something fundamentally not human about me almost.

Lisa returned a number of times to the idea that asexuality was equated with a deficit of humanness - highlighting the cultural view that sexuality is both normal and human, while asexuality is not. Although intellectually, Lisa knew that asexuality was a legitimate identity or orientation, she still felt that it was socially 'wrong'. Cultural messages about what is important and meaningful in life, and her lack of engagement with these aspirations, rendered her lacking. Her view of 'normal' others as caught up with love, relationships and children, made her reluctant to share her own unrelated concerns about work, thus foreclosing opportunities for social contact. Lisa made sense of herself and others in a private, introspective way.

Lisa had found out about asexuality relatively late in life when she was 29 yrs. old after reading an article in The Guardian newspaper. She described an immediate recognition of herself as asexual, although this had few interactional consequences, since she did not come out to anyone afterwards. In fact, the only person Lisa had come out to was a stranger at a conference, in the context of some brief visibility work she did for AVEN. However, this communication was motivated by a desire to depathologise asexuality for others - that is, for political rather than personal reasons.

Lisa's 'story of becoming' (Becker, 1963) was primarily shaped by her own design rather than through interactions with others. As she did not experience romantic attraction and located herself on the far end of the asexual spectrum, there was very little to cause her to come out in interactions. This was not troubling in and of itself, however, because of her (partly held) view that asexuality made her 'less human' in the context of a sexually normative culture. One is left wondering how much this selfperception drove her withdrawal of herself and closed down opportunities for close relationships.

By contrast to her interview, Lisa's diary was empty, apart from some general comments at the end that suggested her engagement in the research process had resulted in new self-reflections. For example, she described a rare moment of connection with a colleague concerning their mutually felt 'outsider status', which left her wondering whether it was hypocritical not to be open with others about her asexuality. In her feedback on the diary-writing process, she mentioned how her empty diary had reflected back to her a starkly asocial life and she wondered again about the connection between her asexuality and asociality. These articulations demonstrate the potential value of a research method to the participant, independently of the researcher's concerns. One view of the empty diary from the latter perspective is that the diary method was ineffectual in this case, for it did not add to a constellation of findings. However, 
another view is that Lisa's empty spaces in the diary deeply confirm what was said in the interview, the silent emptiness of the diary speaking loudly to the lived reality of her life in relation to everyday encounters around intimacy and asexuality.

\section{Conclusion}

Using both interviews and diaries in this research certainly enhanced and deepened our understanding of asexual intimacies and identities. By generating more data, using methods that were differentiated by their reflective time frame, context and mode of data production, our participants provided us with more opportunities to consider issues around asexual identities and intimacies within a 'constellation of findings' (MoranEllis et al, 2006), increasing the potential for multidimensional (Mason, 2006) interpretations of participants' lives.

As expected the diaries and interviews brought different kinds of data to our repertoire of knowledge, as our case studies demonstrate. In all cases, the wide-angle lens of the interview format enabled participants to compartmentalise and make discreet key experiences and interactions around asexuality and its relationship to intimacy and identity. However, as Freya's case showed, an interview can produce both detailed and broad descriptions suggesting that some participants can move between focal points within the same data collection method.

In some cases, the diaries allowed participants to substantiate and elaborate on these key issues, adding a level of descriptive detail that revealed much more complex interrelationships and tensions around asexual identities and intimacies. Idra's detailed diary entries (launched from themes that had been 'flagged' as significant in her interview) demonstrated the effort she invested in, and emphasis she gave to privately managing her negotiations about sex in her new relationship. In this case, too, the micro-level context of the diary was much better at revealing how intimacy and identity were managed in tandem, and the feelings this evoked. The everyday, present time frame of her reflections enabled a different vocabulary to be used: for example, 'going with the flow' in relation to sex, which conveyed her resignation but also troubles the reader in its imputation of desired resistance. Conversely, in Lisa's case, the diary method offered no data, her empty diary reminding us that more methods do not necessarily produce more data, when there is literally nothing to say.

The diaries, with their everyday focus, were also better at showing the relative weight and importance participants attributed to both their asexual identities and intimacy, over time and with daily prompts. The telephoto lens, applied over a two week time frame, allowed microscopic observations of self and other, emotions, and the very precise mechanics and consequences of interactional life. For example, Liam's diary entries 
were richly veined with self-reflective depth and emotion, showing clearly how intersections between asexuality and intimacy created difficulty and trouble in his everyday life, which in turn affected his sense of self. The regularity of particular kinds of experiences and interactions, and the relative space he gave them in the diary, enhanced our understanding of how he managed his troubled intimate relationships.

However, if we shift our focus to the relationship between the two methods in individual cases, a more complex picture emerges. For example, smooth integration and narrative consistency is disrupted by the problem of time, as Bea's case shows. The sequential use of mixed methods showed Bea at more than one point of her life, capturing change, new potentials, and perhaps a side of her that she did not feel comfortable expressing (or deem relevant) in the interview. Here, our use of multiple methods produced two very different accounts of asexual identities and intimacies, which we would not have captured using a single method. Freya's case too illustrates methodological superfluousness in multiple methods research, when someone is able to use one method to achieve as much as two methods might in another case. This highlights the point that multiple methods will not always produce a fuller or a more rounded picture of participants' lives, but can allow each of them to find the most suitable way of telling their story. Participants take up methods and use them with agency, and are not solely directed by the methodological rules.

Some ethical issues remain with mixed methods research, which is not only more demanding of participants' time than single methods, but also has a greater capacity to magnify or uncomfortably reawaken dormant or discarded aspects of personal biography. However, this burden must be balanced against the opportunities afforded to participants for self-reflection and self-knowledge, and the deeper understanding researchers may obtain of these complex social experiences. 


\section{References}

Alaszewski A (2006) Using Diaries for Social Research. London: Sage.

Alexander VD, Thomas H, Cronin A, Fielding J and Moran-Ellis J (2008) Mixed Methods. In: Gilbert N (eds) Researching Social Life. London: Sage, pp 125-144.

AVEN (2015) Asexuality Visibility and Education Network available at: www.asexuality.org/home/ (accessed 2 April 2015).

Bagnoli, A (2004) Researching Identities with Multi-method Autobiographies, Sociological Research Online, 9(2). http://www.socresonline.org.uk/9/2/bagnoli.html (accessed 21 January 2015).

Becker HS (1963) Outsiders: Studies in the Sociology of Deviance. New York: Free Press.

Blaikie N (1993) Approaches to Social Enquiry. Cambridge, UK: Polity Press.

Bogaert A (2004) Asexuality: Prevalence and Associated Factors in a National Probability Sample. Sex Research 41 (3): 279-287.

Bogaert A (2012) Understanding Asexuality. Plymouth: Rowman Littlefield Publishers.

Briggs, CL (1986). Learning how to ask: A sociolinguistic appraisal of the role of the interview in social science research (No. 1). Cambridge University Press. 
Brotto, L, Knudson G, Inksip J, Rhodes K and Erskine Y (2010) Asexuality: A Mixed Methods Approach. Archive of Sexual Behaviour 39 (3): 599-618.

Bryman A (2006) Integrating quantitative and qualitative research: how is it done? Qualitative Research 6(1): 97-113.

Carrigan M (2011) There's More to Life than Sex? Difference and Commonality Within the Asexual Community. Sexualities 14 (4): 462-478.

Cerankowski K J and Milks M (2013) New Orientations: Asexuality and Its Implications for Theory and Practice. Feminist Studies 36: 650-664.

Chasin CJ (2013) Reconsidering Asexuality and its Radical Potential. Feminist Studies 39 (2): 405-426.

Cooley Charles H 1992 [1902]. Human Nature and the Social Order. New Brunswick: Transaction.

Coxon A (1988) "Something Sensational..." The Sexual Diary as a Tool for Mapping Detailed Sexual Behaviour. Sociological Review 36(2): 353-367.

Elliott H (1997) The Use of Diaries in Sociological Research on Health Experience. Sociological Research Online, 2 (2) http://www.socresonline.org.uk/2/2/7.html (accessed 21 October 2014)

Fielding, J, Burningham, K, Thrush D and Catt, R (2007) Public responses to flood warnings. Environment Agency Science Report SC020116. 
Gabb J (2009) Researching Family Relationships: A Qualitative Mixed Methods Approach. Methodological Innovations Online 42 (2): 37-52.

Glaser, BG and Strauss AL (1971). Status Passage. London: Routledge and Kegan Paul.

Greene J Caracell, J and Graham, WF (1989) Toward a Conceptual Framework for MixedMethod Evaluation Designs. Educational Evaluation and Policy Analysis 11(3): 255274 .

Harris C, Jackson L, Mayblin L, Piekut A and Valentine G (2014) "Big Brother Welcomes You": Exploring Innovative Methods for Research with Children and Young People outside of the Home and School Environments. Qualitative Research. Epub ahead of print September 22, 2014, doi: 10.1177/1468794114548947

Harvey L (2002) Intimate Reflections: Private Diaries in Qualitative Research. Qualitative Research 11(6): 664-682.

Hawkes G, Houghton J and Rowe G (2009) Risk and worry in everyday life: Comparing diaries and interviews as tools in risk perception research. Health, Risk \& Society 11(3): 209230.

Holstein JA and Gubrium JF (1995) The active interview (Vol. 37). Sage.

Holstein JA and Gubrium JF (2000) The Self We Live By: Narrative Identity in a Postmodern World. New York: Oxford University Press. 
Jamieson L (1998) Intimacy: Personal Relationships in Modern Societies, Cambridge: Polity Press.

Kelle U (2001) Sociological Explanations Between Micro and Macro and the Integration of Qualitative and Quantitative Methods, FQS (Forum: Qualitative Social Research) 2(1), URL: http://www.qualitative-research.net/fqs/fqs-eng.htm (accessed 12 July 2014).

Kenten C (2010) Narrating Oneself: Reflections on the Use of Solicited Diaries with Diary Interviews. Forum Qualitative Sozialforschung / Forum: Qualitative Social Research, 11:2 (accessed 12 July 2014).

Kinsey AC, Pomeroy WB and Martin C E (1948) Sexual Behavior in the Human Male. Philadelphia, PA: W.B. Saunders.

Markham T and Couldry N (2007) Tracking the reflexivity of the (Dis) engaged citizen: some methodological reflections. Qualitative Inquiry 13(3): 675-695.

Mason J (2006) Mixing methods in a qualitatively driven way. Qualitative Research 6 (9): $9: 25$.

Monrad M (2013) On a scale of one to five, who are you? Mixed methods in identity research. Acta Sociologica 56(4) 347-360. 
Moran-Ellis J, Alexander V D, Cronin A, Dickinson M, Fielding J, Sleney J and Thomas, H (2006). Triangulation and integration: processes, claims and implications. Qualitative research, 6(1) 45-59.

Oakley A (1999) Paradigm wars: some thoughts on a personal and public trajectory. International Journal of Social Research Methdology 2(3): 247-254.

Plummer K (2003). Intimate Citizenship: Private decisions and public dialogues. Washington: University of Washington Press.

Prause N and Graham C (2007) Asexuality: Classification and Characterization. Archives of Sexual Behavior 36 (3): 341-356.

Pryzbolo E (2011) Crisis and Safety: The Asexual in Sexusociety. Sexualities 14 (4): 444-461.

Scherrer, K. (2010) Asexual Relationships: What does Asexuality Have to do with Polyamory? In: Barker M and Langdridge D (eds.) Understanding Non-Monogamies. London: Routledge, pp.154-159

Smart C (2007) Personal Life: New Directions in Sociological Thinking. Cambridge: Polity Press.

Snow, DA and Anderson L (1987). Identity work among the homeless: the verbal construction and avowal of personal identities. American Journal of Sociology 92(6):1336-1371. 
Solberg A (2014) Reflections on interviewing children living in difficult circumstances: courage, caution and co-production. International Journal of Social Research Methodology 17(3): 233-248.

Spowart L and Nairn K (2014) (Re) performing emotions in diary-interviews. Qualitative Research 14(3): 327-340.

Storms, MD, (1980) Theories of sexual orientation. Journal of Personality and Social Psychology 38(5): 783-792.

Van Houdenhove E., Gijs' L, T'Sjoen G and Enzlin P (2014) Stories About Asexuality: A Qualitative Study on Asexual Women. Journal of Sex and Marital Therapy 1-20.

Verbrugge, LM (1980) Health diaries. Medical Care 18(1): 73-95.

Williams R (2000). Making Identity Matter. Durham: Sociologypress.

Wengraf, T. (2001) Qualitative Research Interviewing: Biographic Narrative and SemiStructured Methods. London: Sage. 